\title{
PENGARUH CITRA MEREK DAN KUALITAS PRODUK TERHADAP KEPUTUSAN PEMBELIAN PALUGADA FURNITURE DI KOTA BANDUNG
}

\author{
Indah Widiya Ningsih ${ }^{1}$, R. Aryanti Ratnawati ${ }^{2}$ \\ ${ }^{1,2}$ Universitas Sangga Buana \\ ${ }^{1}$ korespondensi: indahwidiyaningsih36@gmail.com
}

\begin{abstract}
This research aims to identify how the influence of brand image and product quality on purchasing decisions of Palugada Furniture in Bandung City. This research is quantitative. The population of this research is the consumers of Palugada Furniture in the city of Bandung. The illustrations taken were 56 people. The information analysis method uses multiple linear regression analysis, $t$ test and $F$ test. The research results simultaneously prove that there is a positive influence of brand image and product quality on purchasing decisions of Palugada Furniture in Bandung City. Partially brand image and product quality significantly influence purchasing decisions.
\end{abstract}

Keywords: Brand Image, Product Quality And Purchase Decision.

\begin{abstract}
ABSTRAK
Riset ini bertujuan mengenali gimana pengaruh citra merek dan kualitas produk terhadap keputusan pembelian Palugada Furniture Di Kota Bandung. Riset ini berjenis kuantitatif. Populasi dari riset ini merupakan konsumen Palugada Furniture Di Kota Bandung. Ilustrasi yang diambil sebanyak 56 orang. Metode analisis informasi memakai analisa regresi linear berganda, Uji t serta Uji F. Hasil riset secara simultan membuktikan kalau ada pengaruh positif citra merek dan kualitas produk terhadap keputusan pembelian Palugada Furniture Di Kota Bandung. Secara parsial citra merek dan kualitas produk mempengaruhi secara signifikan terhadap keputusan pembelian.
\end{abstract}

Kata Kunci: Citra Merek, Kualitas Produk Dan Keputusan Pembelian.

\section{PENDAHULUAN}

Furniture ialah sebutan perabot rumah tangga yang dengan bersamaan berjalannya waktu tidak cuma mempunyai guna raga saja semacam tempat menyimpan, menaruh benda, digunakan buat duduk serta lain sebagainya saja, hendak namun pula mempunyai guna estetik ataupun keelokan. Yang kerap digunakan buat menata serta memperindah ruangan ataupun rumah ataupun yang kerap diucap dengan Home Décor. Dengan begitu kebutuhan hendak furniture juga terus menjadi bertambah yang membuat para pelakon usaha dalam bidang tersebut bersaing dengan begitu ketat. Terlebih dengan tuntutan konsumen yang senantiasa menginginkan benda dengan model yang baru, menarik, mutu yang baik serta dengan harga yang terjangkau. Sehingga antar pelakon usaha wajib bisa bersaing supaya bisa bertahan dibidang usaha furniture ini. Dari perihal tersebut bisa dikenal kalau saat sebelum melaksanakan keputusan pembelian sesuatu produk terlebih furniture semacam yang dibahas dalam riset ini ialah produk Palugada Furniture tentu terdapat sebagian perihal berarti yang dijadikan pertimbangan ialah dari citra merk serta mutu produk sebab furniture ialah produk yang hendak digunakan bukan dengan jangka 
waktu pendek. Sehingga dalam riset ini penulis mau meyakinkan, mendiskripsikan serta menganalisis gimana pengaruh citra merek dan kualitas produk terhadap keputusan pembelian Palugada Furniture Di Kota Bandung.

\section{TINJAUAN PUSTAKA}

\section{Manajemen}

Manajemen ialah ilmu serta seni buat melaksanakan aksi guna menggapai tujuan[1].

\section{Manajemen Pemasaran}

Manajemen pemasaran merupakan seni serta ilmu memilah sasaran pasar serta memperoleh, melindungi, serta berkembang pelanggan lewat menghasilkan, mengantarkan, serta mengkomunikasikan nilai pelanggan yang unggul[2].

\section{Citra Merek}

Citra merek merupakan deskripsi asosiasi serta kepercayaan konsumen terhadap merk tertentu. Citra merek merupakan pengamatan serta keyakinan yang digenggam konsumen semacam yang di cerminkan di asosiasi' [3]. Dimensi yang membentuk citra merek ialah seperti berikut:

\section{Bukti diri merek( Brand Identity)}

Ialah bukti diri raga yang erat kaitannya terhadap merek atau produk sehingga konsumen mudah mengidentifikasi serta membedakan dengan merek ataupun produk lain, seperti logo, warna, posisi,kemasan, bukti diri industri yang memayungi, slogan serta lain- lain.
1. Personalitas merek( Brand personality) Merupakan kepribadian khas suatu merek yang membentuk karakter tertentu sebagaimana seperti manusia, sehingga Khalayak dapat dengan mudah membedakan dengan merek lain walau dengan jenis produk yang sama, misalnya kepribadian tegas, kaku, berwibawa, ningrat, ataupun murah senyum, hangat, penyayang, berjiwa sosial ataupun dinamis, kreatif, independen, serta sebagainya.

2. Asosiasi merek( Brand association) Merupakan hal- hal khusus yang pantas ataupun senantiasa berhubungan dengan sesuatu merk, umumnya timbul dari penawaran unik sesuatu produk, kegiatan yang kesekian serta tidak berubah misalnya dalam sponsorship ataupun aktivitas social responsibility, isu yang berkaitan dengan merek ataupun seorang.

3. Perilaku serta sikap merek(Brand Attitude serta behavior)

Merupakan perilaku ataupun komunikasi serta interaksi merek kepada konsumen ketika menawarkan keuntungan dan nilai yang dimiliki. Sering suatu merk memakai cara yang dianggap kurang baik serta menyalahi etika ketika berbicara, jika pelayanan juga kurang baik akan mempengaruhi pemikiran publik mengenai perilaku serta sikap merek tersebut, ataupun kebalikannya, perilaku serta sikap simpatik, jujur, tidak berubah- ubah antara 
janji serta kenyataan, jika pelayanan terhadap konsumen baik serta kepedulian mengenai area serta warga akan membentuk anggapan menjadi baik mengenai perilaku serta sikap merek tersebut. Jadi perilaku serta sikap merek mencakup perilaku serta sikap komunikasi, kegiatan serta atribut yang menempel pada merk dikala berhubungan dengan khalayak konsumen, tercantum sikap karyawan serta owner merk.

4. Khasiat serta keunggulan merk( Brand benefit and competence)

Ialah nilai serta keunggulan yang dimiliki suatu merek terhadap konsumen agar dapat merasakan khasiat karena butuh, mau, mimpi serta obsesinya terwujud atas apa yang ditawarkan. Nilai serta keuntungan ini bisa bertabiat fungsional, simbol, ataupun sosial, misalnya merk produk deterjen dengan keuntungan mensterilkan baju (functional benefit), membuat si pengguna baju jika dibersihkan jadi percaya diri (emotional benefit), menjadi bukti gaya hidup warga modern menjadi bersih (symbolic benefit) serta memginspirasi kepada warga agar tidak hirau terhadap kebersihan diri, area serta hati nurani (social benefit). Khasiat, keunggulan serta kompetensi sesuatu merek hendak mempengaruhi citra merk produk, orang ataupun lembaga ataupun industri tersebut[2].

\section{Kualitas Produk}

Kualitas produk merupakan keahlian sesuatu benda buat membagikan hasil ataupun kinerja yang cocok apalagi melebihi dari apa yang di idamkan pelanggan"[2]. Terdapat dimensi kualitas produk seperti berikut:

1. Bentuk

Produk bisa dibedakan secara jelas dengan yang yang lain bersumber pada wujud, dimensi, ataupun struktur raga produk.

2. Identitas Produk

Ciri sekunder ataupun aksesoris yang bermanfaat buat menaikkan guna bawah yang berhubungan terhadap pilihan serta pengembangan produk.

3. Kinerja

Keterikatan terhadap hal fungsional suatu benda serta ciri khas yang jadi pertimbangkan pelanggan saat akan membeli suatu benda.

4. Ketepatan ataupun kesesuaian

Keteriktan dari kecocokan terhadap spesifikasi produk yang diresmikan tadi bersumber pada kemauan konsumen. Kesesuaian terhadap ketepatan ciri desain terhadap ciri kualitas standar produk yang sudah diresmikan.

5. Energi Tahan

Keterikatan terhadap seberapa lama suatu produk bisa dipakai dengan tidak memunculkan permasalahan saat dipakai.

6. Keandalan

Mengenai probabilitas atau mungkin sesuatu benda sukses melaksanakan 
gunanya setiap waktu dipakai dalam jangka waktu serta saat keadaan tertentu juga.

7. Kemudahan Perbaikan

Mengenai seberapa mudah memperbaiki produk jika mengalami kerusakan. Biasanya para konsumen akan memperbaiki sendiri produk bila rusak.

8. Gaya

Tampilan dari produk serta pendapat dari konsumen perihal produk.

9. Desain

Totalitas keistimewaan yang dimiliki produk yang mempengaruhi penampilan serta guna produk dengan kemauan konsumen[2].

\section{Keputusan Pembelian}

Keputusan pembelian merupakan aksi dari konsumen buat ingin membeli ataupun tidak sesuatu produk[4].

Keputusan pembelian memiliki beberapa dimensi seperti :

1. Opsi produk

Pembeli bisa memutuskanan saat akan membeli suatu barang ataupun memakai uang mereka untuk hal lain. Dari hal ini industri harus berfokus terhadap orang yang berminat membeli dan pertimbangan yang pembeli pilih.

2. Opsi merek

Pembeli dapat memutuskan apa nama merek jika hendak dibeli sebab tiap merek mempunyai perbandingan tertentu. Dalam perihal ini industri wajib mengenali gimana konsumen memilah suatu merek.

3. Opsi penyalur konsumen

Konsumen wajib mengambil keputusan tentang penyalur mana yang hendak didatangi. Tiap konsumen berbeda- beda dalam perihal memastikan penyalur dapat disebabkan aspek lokasi terdekat, harga termurah, persediaan barang terlengkap, suasana yang nyaman, luasnya lokasi dan lainnya.

4. Waktu pembelian

Keputusan pembeli ketika memilih waktu saat berbelanja berbeda- beda misalnya ada yang belanja setiap hari, seminggu sekali, 2 minggu sekali dan lain sebagainya.

5. Jumlah pembelian

Pembeli bisa memutuskan seberapa banyak produk yang akan dibeli dalam satu waktu belanja. Hal ini industri wajib mempersiapkan banyaknya produk cocok dengan kemauan yang berbeda- beda.

6. Tata cara pembayaran

Konsumen bisa mengambil keputusan tentang tata cara pembayaran yang hendak dicoba dalam pengambilan keputusan memakai produk ataupun jasa. Dikala ini keputusan pembelian tidak cuma dipengaruhi oleh aspek area serta keluarga, keputusan pembelian juga terpengaruh dengan teknologi yang digunakan pada transaksi pembelian[4].

Dari sebagian penafsiran diatas sehingga bisa ditarik kesimpulan menimpa paradigma dalam 
riset ini. Paradigma riset merupakan pola ikatan antara variabel yang hendak di teliti.[5].

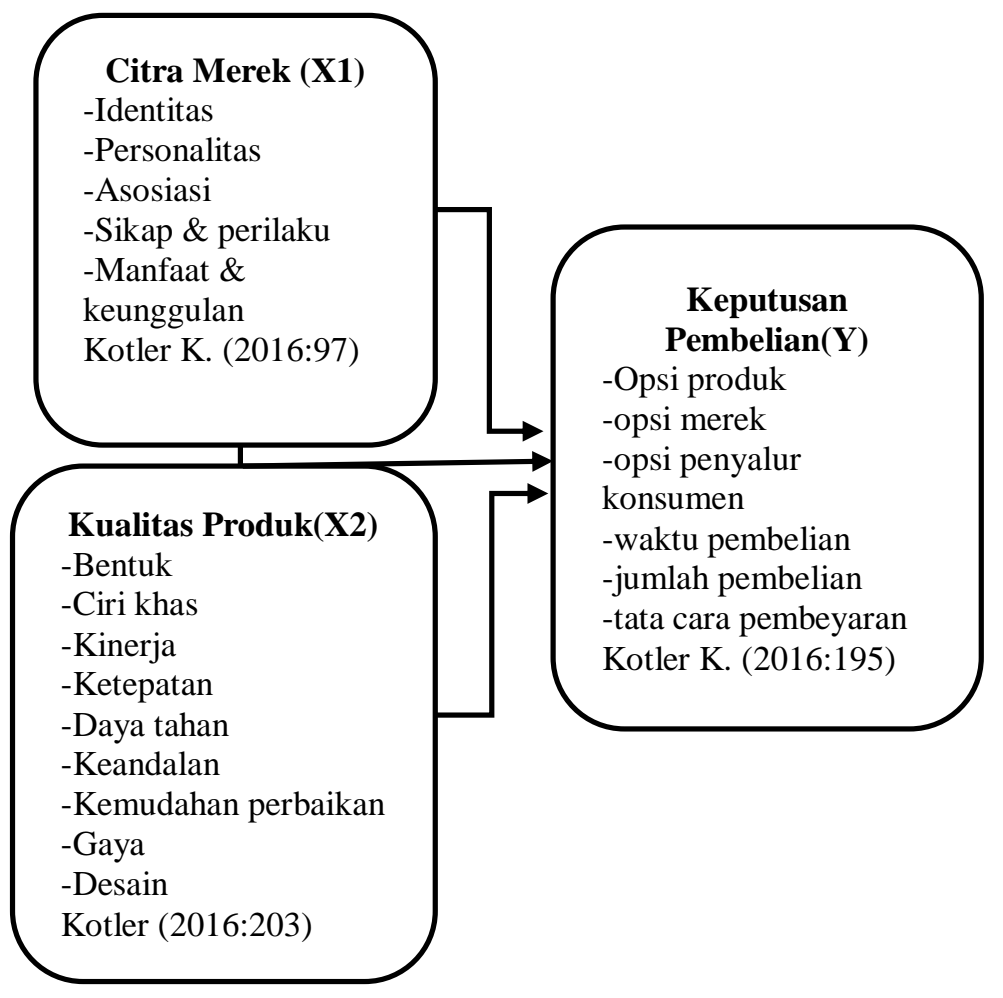

\section{Gambar 1 : Paradigma Penelitian}

Sehingga bisa diambil hipotesis ataupun dugaan. Hipotesis pula bisa dinyatakan selaku jawaban teoritis terhadap rumusan permasalahan riset, belum jawaban yang empirik[5]. Hipotesis dalam riset ini:" Citra Merek dan Kualitas Produk Mempengaruhi secara parsial ataupun simultan".

\section{METODE PENELITIAN}

Tata cara riset yang digunakan dalam riset ini ialah riset kuantitatif. Dengan sumber informasi primer yang berasal dari konsumen Palugada Furniture Di Kota Bandung dengan ilustrasi 56 responden yang berasal dari 127 populasi dengan metode pengumpulan tiba dengan metode menyebarkan kuesioner. Riset ini memakai pendekatan deskriptif verifikatif. Dengan variabel leluasa citra merk serta mutu produk, sebaliknya variabel terikat keputusan pembelian. Dengan pengukuran memakai skala likert, selaku berikut: 
ISBN 978-623-92199-2-5

Tabel 1 : Skala Likert

\begin{tabular}{|c|c|c|}
\hline Nilai & Simbol & Keterangan \\
\hline 5 & SS & Sangat Setuju \\
\hline 4 & S & Setuju \\
\hline 3 & CS & Cukup Setuju \\
\hline 2 & KS & Kurang Setuju \\
\hline 1 & TS & Tidak Setuju \\
\hline
\end{tabular}

[5]

Dengan hasil jawaban kuesioner yang berupa data ordinal dan ditransformasikan menjadi data interval dahulu dengan menggunakan Method Succesive Interval (MSI) yang selanjutnya akan dilakukan uji validitas, uji reliabilitas, normalitas serta analisis regresi linear berganda dengan menggunakan bantuan program SPSS 26 (Statistical Program and Service Solution 26).

\section{HASIL DAN PEMBAHASAN}

Riset yang dilakukan pada konsumen Palugada Furniture Di Kota Bandung dengan jumlah sampel 56 responden dari total jumlah populasi sebanyak 127 orang. Dengan didominasi oleh konsumen yang berjenis kelamin perempuan, dengan dominasi usia 20-25 tahun, yang didominasi pelajar/mahasiswa dengan jumlah penghasilanRp.3.000.000,00-Rp.4.000.000,00 /bulan. Dengan hasil Uji F, model regresi dan koefisien determinasi yang merupakan hasil dari output SPSS 26 sebagai berikut:

Tabel 2 : Hasil Uji F

\begin{tabular}{|l|l|r|r|r|r|c|}
\hline \multicolumn{7}{|c|}{ ANOVA $^{\mathbf{a}}$} \\
\hline \multicolumn{2}{|l|}{ Model } & Sum of Squares & \multicolumn{1}{|c|}{ Df } & \multicolumn{1}{c|}{ Mean Square } & F & \multicolumn{1}{c|}{ Sig. } \\
\hline \multirow{3}{*}{1} & Regression & 1834020963.431 & 2 & 917010481.715 & 44.997 & $.000^{\mathrm{b}}$ \\
\cline { 2 - 8 } & Residual & 1080109205.409 & 53 & 20379418.970 & & \\
\cline { 2 - 8 } & Total & 2914130168.839 & 55 & & & \\
\hline
\end{tabular}

a. Dependent Variable: Keputusan Pembelian (Y)

b. Predictors: (Constant), Kualitas Produk (X2), Citra Merek(X1)

Dengan nilai :

$$
\begin{array}{ll}
\alpha & =5 \% \\
\text { df1 } & =\mathrm{k}=2 \\
\text { df2 } & =\mathrm{n}-\mathrm{k}-1=56-2-1=53
\end{array}
$$

Dari hasil $F_{\text {hitung }}$ didapat 44,997 serta nilai $F_{\text {tabel }}$ yaitu 3,172. Kriteria pengujia ialah, "tolak Ho jika $F_{\text {hitung }}>F_{\text {tabel" }}$. Dari hasil tersebut didapat nilai $F_{\text {hitung }}=44,997>F_{\text {tabel }}=3,172$,sehingga $\alpha$ $=5 \%$ maka $\mathrm{H}_{0}$ ditolak yang berarti bahwa variabel citra merek dan kualitas produk berpengaruh terhadap keputusan pembelian secara simultan. 
Tabel 3 : Hasil Uji Regresi Linear Berganda

\begin{tabular}{|c|c|c|c|c|c|c|}
\hline \multicolumn{7}{|c|}{ Coefficients $^{\mathbf{a}}$} \\
\hline \multirow{2}{*}{\multicolumn{2}{|c|}{ Model }} & \multicolumn{2}{|c|}{$\begin{array}{l}\text { Unstandardized } \\
\text { Coefficients }\end{array}$} & \multirow{2}{*}{$\begin{array}{c}\text { Standardized } \\
\text { Coefficients } \\
\text { Beta }\end{array}$} & \multirow[t]{2}{*}{$\mathrm{T}$} & \multirow{2}{*}{ Sig. } \\
\hline & & $\mathrm{B}$ & Std. Error & & & \\
\hline \multirow{3}{*}{1} & (Constant) & 5393.896 & 3433.844 & & 1.571 & .122 \\
\hline & Citra Merek (X1) & .490 & .146 & .500 & 3.366 & .001 \\
\hline & $\begin{array}{l}\text { Kualitas Produk } \\
\text { (X2) }\end{array}$ & .334 & .152 & .328 & 2.206 & .032 \\
\hline
\end{tabular}

a. Dependent Variable: Keputusan Pembelian (Y)

Dari hasil hitung pada tabel 3 diketahui bentuk persamaan regresi linier berganda seperti dibawah:

$$
Y=a+\beta_{1} X_{1}+\beta_{2} X_{2}+e
$$

$\mathrm{Y}=5393.896+0.490 \mathrm{X}_{1}+0.334 \mathrm{X}_{2}+\mathrm{e}$

Keterangan:

$\mathrm{Y}=$ Variabel $\quad$ Keputusan

Pembelian/Dependen

$\mathrm{X}_{1}=$ Variabel Citra Merek/Independen

$\mathrm{X}_{2} \quad=$ Variabel

Kualitas

Produk/Independen

$\beta_{1} \beta_{2} \quad=$ Koefisien Regresi

$\alpha=$ Koefisien Konstanta

$e \quad=$ Standar error

Jadi persamaan regresi tersebut dapat dijelaskan sebagai berikut:

a. Nilai koefisien regresi variabel Citra Merek (X1) sebesar 0,490 artinya jika variabel independen lain nilai tetap (konstan) dan citra merek meningkat satu satuan, sehingga variabel keputusan pembelian (Y) menjadi meningkat sebesar 0,490.

b. Nilai koefisien regresi variabel Kualitas Produk (X2) 0,334 dapat diketahui jika variabel independen lain dengan nilai tetap (konstan) serta variabel kualitas produk meningkat sebesar satu satuan, maka keputusan pembelian(Y) akan meningkat sebesar 0,334 .

Berdasarkan analisis tersebut, dapat dijelaskan adanya pengaruh atau keeratan hubungan antara variabel citra merek dan kualitas produk/independen terhadap variabel keputusan pembelian/dependen.

Tabel 4 : Hasil Uji Koefisien Determinasi

\begin{tabular}{|l|r|r|r|r|}
\hline \multicolumn{5}{|c|}{ Model Summary $^{\mathbf{b}}$} \\
\hline Model & $\mathrm{R}$ & R Square & $\begin{array}{c}\text { Adjusted R } \\
\text { Square }\end{array}$ & $\begin{array}{c}\text { Std. Error of the } \\
\text { Estimate }\end{array}$ \\
\hline 1 & $.793^{\mathrm{a}}$ & .629 & .615 & 4514.357 \\
\hline
\end{tabular}

a. Predictors: (Constant), Kualitas Produk (X2), Citra Merek(X1)

b. Dependent Variable: Keputusan Pembelian (Y) 
Besar angka koefisien determinasi ataupun $\mathrm{R}$ Square yaitu 0,629 atau $62,9 \%$. Nilai itu dapat diartikan jika variabel citra merek dan kualitas produk secara positif serta signifikan mempengaruhi variabel Keputusan Pembelian Palugada Furniture Di Kota Bandung sebesar $62,9 \%$, dengan sisa $37,1 \%$ diakibatkan variabel lain. Pernyataan tersebut diperkuat dengan beberapa penelitian terdahulu sebagai berikut dengan $\mathrm{R}$ square yaitu $63,6 \%$ yang menjelaskan jika secara positif dan signifikan citra merek dan kualitas produk mempengaruhi keputusan pembelian dengan sisa 36,4\% akibat variabel lain[6]. Penelitian lain dengan $\mathrm{R}$ Square sebesar 0,506 atau sebesar 50.6\%. Dapat diketahui jika secara positif dan signifikan Citra Merek dan Kualitas Produk mempengaruhi Keputusan Pembelian ialah $50.6 \%$ dengan sisa $49.4 \%$ diakibatkan variabel lain[7]. Lalu menurut penelitian lain Koefisien Determinasi atau $R$ Square yaitu 0,697, artinya variabel independen yaitu variabel Citra Merek dan Kualitas Produk secara positif dan signifikan berpengaruh terhadap Keputusan Pembelian sebesar 69,7\%, dengan sisa $30,3 \%$ diakibatkan variabel lain[8]. Menurut penelitian lain $R$ Square sebesar 0,220 artinya variabel Citra Merek dan Kualitas Produk secara positif serta signifikan mempengaruhi Keputusan Pembelian yaitu $22 \%$, dengan sisa $78 \%$ diakibatkan variabel lain[9]. Dan penelitian lain dengan $\mathrm{R}$ Square sebesar 0,304 yang artinya variabel Citra Merek dan Kualitas Produk mempengaruhi secara positif serta signifikan yaitu 30,4\% dengan sisa $69,6 \%$ yang terpengaruh oleh variabel lain[10].

\section{KESIMPULAN}

Setelah dilakukan penelitian ini peneliti mengambil kesimpulan jika dari hasil uji didapat bahwa variabel citra merek dan kualitas produk mempengaruhi keputusan pembelian sebesar 62,9\%. Dari hasil pengujian statistik didapatkan bahwa variabel citra merek dan kualitas produk mempengaruhi keputusan pembelian karena t-hitung > t-tabel yang artinya Ha diterima dan Ho ditolak.

\section{DAFTAR PUSTAKA}

[1] Siswanto, "Pengantar Manajemen," Jakarta: PT.Bumi Aksara, 2015.

[2] P. Kotler and K. L. Keller, Marketing Mangement. 2016.

[3] Tjiptono, "Strategi Pemasaran (edisi 4)," Yogyakarta: Andi, 2015.

[4] Philip Kotler dan Gary Armstrong, Dasar-dasar pemasaran jilid 1, vol. 2004, no. 2004. 2003.

[5] Sugiyono, METODE PENELITIAN (Pendekatan Kuantitatife, Kualitatif, dan $R \& D)$. Bandung: CV. ALFABETA, 2017.

[6] T. F. Sari, "Pengaruh Citra Merek Dan Kualitas Produk Terhadap Keputusan Pembrlian Produk Pond's (Studi Kasus Pada Mahasiswi FEBI UIN Sumatera Utara)," Thesis (Skripsi(S1), p. 106, 2018, [Online]. Available: http://repository.uinsu.ac.id/4554/1/Skrip siTryaFattikaSari.pdf\%0A. 
[7] R. D. Wulandari and D. A. Iskandar, "PENGARUH CITRA MEREK DAN KUALITAS PRODUK TERHADAP KEPUTUSAN PEMBELIAN PADA PRODUK KOSMETIK," J. Ris. Manaj. dan Bisnis Fak. Ekon. UNIAT, vol. 3, no. 1, pp. 11-18, 2018, doi: 10.36226/jrmb.v3i1.81.

[8] P. Y. Radityasari, "ANALISI PENGARUH CITRA MEREK DAN KUALITAS PRODUK TERHADAP KEPUTUSAN PEMBELIAN SEPATU NIKE (Studi Kasus pada Mahasiswa Kampus I Mrican Universitas Sanata Dharma Yogyakarta)," p. 33, 2018.
[9] J. Saleh, "Pengaruh Citra Merek dan Kualitas Produk terhadap Keputusan Pembelian Sepatu Merek Vans," J. Ekon. dan kewirausahaan, vol. 3, no. 3, pp. 6678, 2018.

[10] S. AMILIA, "Pengaruh Citra Merek, Harga, dan Kualitas Produk terhadap Keputusan Pembelian Handphone Merek Xiaomi di Kota Langsa," J. Manaj. dan Keuang. Unsam, vol. 6, no. 1, pp. 660669, 2017. 